\title{
LC3A-Positive Light Microscopy Detected Patterns of Autophagy and Prognosis in Operable Breast Carcinomas
}

\author{
Efthimios Sivridis, ${ }^{*}$ Michael I. Koukourakis, ${ }^{\dagger}$ \\ Christos E. Zois, ${ }^{\dagger}$ Ioanna Ledaki, ${ }^{\ddagger}$ \\ David J.P. Ferguson, ${ }^{\ddagger}$ Adrian L. Harris, ${ }^{\ddagger}$ \\ Kevin C. Gatter, ${ }^{\ddagger}$ and Alexandra Giatromanolaki* \\ From the Departments of Pathology, and Radiotherapy/ \\ Oncology, ${ }^{\dagger}$ Democritus University of Thrace and University \\ General Hospital of Alexandroupolis, Alexandroupolis, Greece; \\ and the Cancer Research UK, Molecular Oncology Laboratories, ${ }^{\ddagger}$ \\ Weatherall Institute of Molecular Medicine and the Department \\ of Clinical Laboratory Science University of Oxford, John \\ Radcliffe Hospital, Oxford, United Kingdom
}

Autophagy is a self-degradation mechanism by which cells recycle their own cytoplasmic constituents and dispose of excess or defective organelles after starvation and oxygen deprivation. An antibody to the microtubule-associated protein 1 light chain 3 (LC3A), recognizing both the soluble (LC3A-I) and the membrane-bound form (LC3A-II) of the protein, was used to detect autophagic activity in 102 breast carcinomas. Three distinct patterns were recognized: (1) diffuse cytoplasmic, (2) cytoplasmic/juxta-nuclear, and (3) "stone-like" pattern - dense, rounded, amorphous structures, $5 \mu \mathrm{m}$ on average, typically enclosed within cytoplasmic vacuoles. The diffuse cytoplasmic pattern showed a direct association with estrogen and progesterone receptor expression. The juxta-nuclear pattern indicated a similar association with hormone receptors, an inverse association with tumor size, and a favorable prognosis. By contrast, an increased number of stonelike structures, probably representing an excessive autophagic response, was related to high-grade tumors and a less favorable outcome. Interestingly, 60 additional epithelial tumors of nonbreast origin disclosed identical autophagic patterns, and so did MDA231 breast cancer xenografts and HCT116 colon tumor spheroids (also analyzed by electron microscopy). Moreover, MCF-7 human breast cancer cell lines confirmed induction of LC3A by anoxia and Thapsigargin. It is concluded that autophagy can be readily recognized in breast carcinomas by light microscopy, after immunohistochemical staining with LC3A, but the signifi- cance of the various patterns expressed would need further evaluation. (AmJ Pathol 2010, 176:2477-2489; DOI: 10.2353/ajpath.2010.090049)

Cancer cells survive the adverse conditions of the extracellular milieu (i.e., hypoxia, nutrient deprivation, and reduced growth factors) through angiogenesis and anaerobic glycolysis. ${ }^{1}$ Yet rapidly proliferating malignant neoplasms, having high metabolic demands, are not sufficiently supplied by these processes. ${ }^{2-6}$ An alternative metabolic pathway for providing energy, when both oxygen and glucose are depleted, is autophagy - a self-degradation mechanism by which cells recycle their own cytoplasmic constituents and dispose of excess or defective organelles resulting in protein and ATP synthesis. ${ }^{7-9}$ However, autophagy when prolonged can also cause cell death, but how the outcome is determined and the relationship of autophagy to clinical outcome is, at present, poorly understood.

Angiogenesis and anaerobic glycolysis (i.e., the shifting from oxidative phosphorylation to anaerobic metabolism) have both been studied extensively in relation to malignant disease, including breast cancer. ${ }^{10-15}$ The activation of antiapoptotic pathways, as a complementary cell surviving mechanism, has also been considered in a number of studies. ${ }^{16,17}$ By contrast, the phenomenon of autophagy only recently received attention for its biological significance in human malignancies. It is now known, for example, that under suboptimal microenvironmental conditions, cytoplasmic constituents are first entrapped by a membrane sac, called the isolation membrane, which subsequently closes to form double membrane structures, called autophagosomes or autophagic vacuoles.

Supported by the Tumor and Angiogenesis Research Group, the Cancer Research, UK, and the Oxford NIHR Biomedical Research Center Programme.

Accepted for publication January 11, 2010

Supplemental material for this article can be found on http://ajp. amjpathol.org

Address reprint requests to Alexandra Giatromanolaki, M.D. Democritus University of Thrace, Alexandroupolis 68100, Greece. E-mail: agiatrom@med.duth.gr. 
These, and specifically their outer membrane, are fused with lysosomes producing autolysosomes. ${ }^{8,18}$ Lysosomal hydrolases degrade the cytoplasmic contents of the autophagosome, together with its inner membrane, ${ }^{8,18}$ and the resulting macromolecules are recycled. Failure to accomplish this self-degradation process, probably because of overload of cytoplasmic components, enzyme exhaustion, or lysosomal enzyme defects, leads to accumulation of debris and massive destruction of tumor cells. ${ }^{18-21}$

Increased new blood vessel formation is associated with rapidly advancing tumors. ${ }^{10,12,13}$ Equally, high levels of hypoxia are indicative of tumor aggressiveness. ${ }^{11,22-24} \mathrm{Be}-$ sides, an activated antiapoptotic pathway contributes to tumor growth and progression. ${ }^{25}$ Tumor hypoxia and accelerated angiogenesis have both been used as markers of poor prognosis for a variety of tumors, including breast cancer. ${ }^{10-13,22,26}$ Nonetheless, the role of autophagy remains, by and large, obscure in this respect. Is it a favorable or an unfavorable prognostic indicator in human breast malignancies?

This study was designed to investigate this question in a series of 102 operable breast carcinomas. However, rather than using electron or fluorescence microscopy, this study uses light microscopy after immunohistochemical staining with an antibody recognizing the autophagyrelated protein Atg8 (microtubule associated protein 1 light chain 3 MAP1LC3A or LC3A), an essential component of the autophagic machinery. ${ }^{27,28} \mathrm{LC} 3 \mathrm{~A}-\mathrm{II}$ is derived from a proLC3 $30-\mathrm{KDa}$ protein after cleavage by autophagin Atg 4 to produce the active cytosolic form LC3A-I $(18 \mathrm{kDa})$. After activation by Atg7, LC3A-I is transferred to Atg3 and subsequently converted into the membranebound form LC3A-II. ${ }^{8,28}$ The latter localizes on the isolation membranes and the complete spherical autophagosomal and autolysosomal membranes, forming a suitable marker of autophagic activity.

\section{Materials and Methods}

\section{Breast Tumor Specimens and Patients Characteristics}

This study was based on 102 consecutive cases of operable breast carcinomas having a diameter of $2 \mathrm{~cm}$ or less and no palpable axillary lymph nodes suspicious of disease before surgery. All specimens had been fixed in $10 \%$ formal saline and processed routinely to paraffin wax. The original hematoxylin and eosin (H\&E)-stained sections were reviewed and the cases selected were confirmed as being invasive ductal carcinomas, not otherwise specified (NOS), grade G1 to G3. Histological types other than NOS were excluded from this study to assure homogeneity of the sample. Care was taken to select specimens that contained abundant cancer tissue for immunohistochemistry; however, there were 11 cases among the 102 chosen which showed areas of noncancerous breast tissue adjacent to invasive carcinomas.

The patients in the series ranged in age from 32 to 75 years, with a median of 56 years at the time of operation. The primary mode of treatment was a modified radical mastectomy with extensive axillary lymph node dissection, performed between the years 1986 and 2002. Although of preoperative stage I, these patients were of stage I to IIIA pathology (American Joint Committee on Cancer [AJCC]). Patients with estrogen receptor-positive tumors received tamoxifen for at least five years, whereas those having more than three positive lymph nodes received CMF or anthracycline based chemotherapy. None of the patients received radiotherapy or neoadjuvant chemotherapy.

The median follow-up period was 89 months (range, 4 to 137 months), and during this time 68/102 (66.7\%) patients were alive for analysis.

\section{Other Epithelial Tumor Specimens}

To investigate whether or not the autophagy patterns described for human breast carcinomas would occur in other epithelial malignancies, a series of 60 human tumors, including 20 colon adenocarcinomas and an equal number of endometrial and prostatic adenocarcinomas, were stained immunohistochemically for LC3A.

\section{The Primary Antibody MAP1LC3A}

The purified rabbit polyclonal antibody MAP1LC3A (Abgent, San Diego, CA), raised against a synthetic peptide at the C-terminal cleavage site of the human cleaved MAP1LC3A, was used for detecting autophagy (Table 1). The immunogen sequence of the autophagy cleaved-LC3 antibody MAP1LC3A (AP1805a) at the C-terminal cleavage site of the human cleaved-LC3 (APG8a) is: DEDGFLYMVYASQETFG aa 104-120 (personal communication). The antibody is capable of detecting both the LC3-I and LC3-II forms, although only the LC3-II form is membrane-bound localized on the autophagosomal membrane. This particular antibody was selected among two other commercially available, as showing an improved antigenic reactivity compared with those tested in parallel.

Table 1. Details of the Antibodies, Dilutions, and Antigen Retrieval Methods Used in this Study

\begin{tabular}{|c|c|c|c|c|}
\hline Primary antibody & Dilution/incubation time & Antigen retrieval & Specificity & Source \\
\hline AP1805a & 1:20 (overnight*) & MW & LC3A & Abgent, San Diego, CA \\
\hline $1 \mathrm{D} 5$ & $1: 100\left(60\right.$ minutes $\left.^{\dagger}\right)$ & MW & ER & Dako, Denmark \\
\hline $1 \mathrm{~A} 6$ & $1: 100\left(60\right.$ minutes $\left.^{\dagger}\right)$ & MW & $\mathrm{PgR}$ & Dako, Denmark \\
\hline NLC-CB11 & $1: 20\left(75\right.$ minutes $\left.^{\dagger}\right)$ & MW & c-erbB-2 & Novokastra, UK \\
\hline
\end{tabular}

${ }^{*}$ At $4^{\circ} \mathrm{C}$.

${ }^{\dagger}$ At room temperature.

MW indicates microwave heating. 


\section{A Pilot Study for MAP1LC3A}

To establish the optimum concentration (titer) and incubation time for the primary MAP1LC3A (AP1805a) antibody, a series of breast tumors were used in a pilot study. First, the positivity of the test tissues was acquired, using the manufacturer's recommended dilution 1:100. Subsequently, the MAP1LC3A was applied in dilutions of 1:10, $1: 20,1: 50,1: 100,1: 200,1: 400$, and different incubation times (75 minutes room temperature versus overnight at $4^{\circ} \mathrm{C}$ ) to numbered serial sections. The dilution giving the best contrast between the apparently positive malignant epithelial cells and the surrounding tumor stroma with minimal background staining was 1:20 after overnight incubation.

\section{The Immunohistochemical Method for Autophagy}

Autophagy was detected by a standard immunohistochemical technique using the purified rabbit polyclonal antibody MAP1LC3A (AP1805a; Abgent, San Diego, CA; Table 1).

Sections were cut at $3 \mu \mathrm{m}$ and stained as follows: They were dewaxed and rehydrated in graded alcohol solutions. For heat-induced epitope retrieval, the sections were placed in citrate buffer (1:10 dilution, $\mathrm{pH}$ 7.2) and heated at $120^{\circ} \mathrm{C}$ for $3 \times 5$ minutes. Endogenous peroxidase activity was neutralized using Peroxidase Block for 5 minutes. The nonspecific binding was blocked by preincubation with Protein Block for 5 minutes at room temperature (Novocastra Laboratories Ltd, Newcastle on Tyne, UK). Slides were then incubated overnight at $4^{\circ} \mathrm{C}$ with MAP1LC3A (AP1805a) primary antibody diluted 1:20 (Abgent, San Diego, CA). The slides were washed with PBS $(2 \times 5$ minutes $)$ and then incubated with Post Primary Block (that enhances penetration of the subsequent polymer reagent) for 30 minutes at room temperature (Novocastra Laboratories Ltd, Newcastle on Tyne, UK), then washed with PBS for $2 \times 5$ minutes and incubated with Novo Link polymer for 30 minutes at room temperature (Novocastra Laboratories Ltd, Newcastle on Tyne, UK). This recognizes mouse and rabbit immunoglobulins and detects any tissue-bound primary antibody. After extensive washing with PBS $(2 \times 5$ minutes), the color reaction was developed in DAB (3,3'-diaminobenzidine) for 5 minutes. The sections were then counterstained with hematoxylin, dehydrated, and mounted.

\section{Controls}

Normal rabbit immunoglobulin-G was substituted for the primary antibody as negative control. Staining with omission of the primary antibody was also performed as negative control.

\section{Evaluation of Autophagic Activity}

After immunohistochemical staining of breast tumors for LC3A protein, three distinct patterns of cytoplasmic ex- pression were recognized: diffuse cytoplasmic, cytoplasmic/juxta-nuclear, and a stone-like pattern (see "Results"). These were evaluated separately for the extent and the intensity of staining as follows:

The number of tumor cells with a diffuse cytoplasmic pattern was recorded in all available fields at $200 \times$ magnification and expressed as the mean of all counts. Tissues with a strong cytoplasmic staining in more than 50\% of tumor cells were considered as having a high cytoplasmic LC3A reactivity. The remaining cases were assigned to low cytoplasmic reactivity, as the proportion of positive neoplastic cells was not exceeding that of $10 \%$ (0 to $10 \%$ ).

The juxta-nuclear intense staining of the cytoplasm was determined in ten randomly selected fields per section at $1000 \times$ magnification and expressed as the sum of all counts. The tumors were subsequently classified into groups of low, intermediate, and high reactivity according to 33rd and 66th percentile.

The stone-like pattern was evaluated in a manner analogous to that of the juxta-nuclear; it was expressed as the sum of the ten counts at $1000 \times$ magnification, and classed into three tumor groups (low, intermediate, and high) on the basis of 33rd and 66th percentile.

Tissues were examined under a light microscope (Nikon, model eclipse E400). At all times, the described patterns of autophagic LC3A reactivity were visible at 100x, $200 \times$, and $400 \times$ optical fields; however, the juxta-nuclear and stone-like structures were examined under oil immersion lens at a magnification corresponding to the lower limits of electron microscopy (1000x), as a mean between the two methodologies.

Measurements of autophagic structures were performed by Nikon software NIS Elements Advanced Research (AR).

\section{Evaluation of ER, PgR, and c-erbB-2}

ER and PgR values were calculated as a percentage of cancer cells showing nuclear reactivity within a given cell population; all optical fields were counted in each case at $200 \times$ and expressed as the mean of all counts. Tumors with ER or PgR values $>20 \%$ were considered as positive. Nuclear expression in more than $20 \%$ of tumor cells was recorded in 64/102 (62.7\%) operable breast carcinomas after immunohistochemical staining for ER, and 52/102 (50.9\%) neoplasms after staining for PgR. The range of expression was in both cases 0 to $100 \%$, but the median value was $60 \%$ for the former and $10 \%$ for the latter.

c-erbB-2 was evaluated following a similar approach to $\mathrm{ER}$ and $\mathrm{PgR}$, and tumors expressing cell membrane reactivity in $>30 \%$ of neoplastic cells were considered positive. Such an expression was noted in 54/102 (52.9\%) of tumors, and varied from $0 \%$ to $100 \%$ with a median value of $30 \%$. It is appreciated that in our series c-erbB-2 positivity was rather higher, as indeed in others, ${ }^{29}$ compared with $20 \%$ to $35 \%$ rate reported in the literature.

In all cases, the histological material was evaluated without prior knowledge of the patients' clinical course. 
The scoring of cases was performed separately by two independent observers, and discrepancies were resolved on the conference microscope. The results of autophagic activity were subsequently related to tumor size, tumor grade, number of lymph nodes involved with metastasis, ER, PgR, and c-erbB-2 (HER-2) status, and also to patients survival.

\section{Western Blotting}

Tissue was homogenized as described by Laemmli. ${ }^{30}$ Total protein concentrations for the fractions were estimated according to the method of Lowry et al. ${ }^{31}$ Protein extracts $(15 \mu \mathrm{g})$ were separated on $12.5 \%$ SDS-PAGE gels and transferred to membranes. Primary antibody (MAP1LC3A, Abgent, San Diego, CA) was added at 1:500 dilution and incubated overnight at $4^{\circ} \mathrm{C}$, hybridized for 2 hours at room temperature with appropriate secondary antibody, rinsed, and developed in TMB (KPL Laboratories, Gaithersburg, MD). Equal protein loading was verified by Coomassie staining.

\section{Tumor Spheroids and Xenografts}

Formalin-fixed paraffin-embedded tissues from HCT116 colon cancer spheroids and MDA231 breast xenografts were used to assess immunohistochemical patterns of LC3A expression.

Thus, for spheroid experiments, HCT116 colon cancer cells were cultured in McCoy's 5A supplemented with $10 \%$ fetal bovine serum. Aggregation of cells into spheroids was initiated by plating $4 \times 10^{6}$ in a spinner flask containing $250 \mathrm{ml}$ standard growth medium and spinning (Techne MCS, UK) at 40 r.p.m for 7 days. On day 7 the spheroids were soaked in neutral buffered formalin overnight. Next day they were embedded in $4 \%$ agarose and placed in tissue cassettes and submerged in neutral buffered formalin. Cassettes were embedded in paraffin. Serial sections of $4 \mu \mathrm{m}$ were cut, and they were placed on charged microscope slides and dried overnight. The formalin-fixed paraffin embedded spheroids were used to assess immunohistochemical patterns of LC3A expression.

For xenografts, all protocols were performed under Home Office legislation. ${ }^{32}$ The cells (10 ${ }^{7}$ MDA231) were implanted into 6- to 8-week-old female BALB/C SCID mice (Harlan Sprague Dawley, Inc., Indiana) s.c. with 100 $\mu l$ of cell suspension with an equal volume of Matrigel (BD Bioscience). Each group consisted of five mice. Tumor growth was monitored and measured using calipers. Tumor volume was calculated from a formula $(L \times$ $\mathrm{W} \times \mathrm{H} \times 0.52)$. Treatments with bevacizumab were injected i.p. every three days at a dose of $10 \mathrm{mg} / \mathrm{kg}$. Tumor growth was monitored twice to thrice every week by measuring the length, width, and height of each tumor using calipers. Tumor volumes were calculated from the formula $\mathrm{L} \times \mathrm{W} \times \mathrm{H} / 0.52$. When a tumor reached the maximum size $\left(1.44 \mathrm{~cm}^{2}\right.$ surface area) permitted by the Home Office license, the mouse was sacrificed and the tumor was excised. Paraffin embedded tissue blocks from formalin-fixed tumor samples were sectioned, dewaxed, and rehydrated using standard techniques.

\section{Electron Microscopy}

The tumor spheroids were fixed in $4 \%$ glutaraldehyde in $0.1 \mathrm{M}$ phosphate buffer and processed for routine electron microscopy as described previously. ${ }^{33}$ In summary, the samples were postfixed in osmium tetroxide, dehydrated in ethanol, treated with propylene oxide, and embedded in Spurr's epoxy resin. One- $\mu \mathrm{m}$ sections were stained with Azure A for light microscopy and thin sections stained with uranyl acetate and lead citrate for electron microscopy.

\section{Cell Experiments}

The human breast cancer cell line MCF-7 was provided by Cancer Research UK. Cells were maintained in DMEM (with $4.5 \mathrm{mg} / \mathrm{ml}$ glucose) supplemented with $10 \%(\mathrm{v} / \mathrm{v})$ FCS, penicillin (100 U/ml), streptomycin $(100 \mathrm{mg} / \mathrm{ml})$, and $4 \mu \mathrm{mol} / \mathrm{L}$ L-glutamine (Life Technologies). A humidified gas-sorted anoxic incubator-gloved box (In $\mathrm{VivO}_{2}$ 400; Ruskin, Leeds, UK) was used for anoxic experiments resulting in $5 \% \mathrm{H}_{2}, 5 \% \mathrm{CO}_{2}$, and $90 \% \mathrm{~N}_{2}$. Humidity level was greater than $90 \%$. The effect of an agent that mediates endoplasmic reticulum stress, namely Thapsigargin (at concentration of $300 \mathrm{nmol} / \mathrm{L}$ for 24 hours; Calbiochem), on LC3 protein expression in cancer cells was also examined.

The Immunoblot analysis was performed as follows: After treatment, cells were washed in ice-cold PBS and lysed in $2 \times$ sample buffer ( $125 \mathrm{mmol} / \mathrm{L}$ Tris [pH 6.8], 4\% sodium dodecyl sulfate, $0.01 \%$ bromophenol blue, $10 \%$ $\beta$-mercaptoethanol, $10 \%$ glycerol). Whole cell lysates were resolved on SDS-PAGE, electroblotted onto polyvinylidene difluoride membrane (Millipore), and probed with the indicated antibodies. Horseradish peroxidiseconjugated anti-rabbit or anti-mouse antibodies (Dako Irc.) were used with ECL Plus system (Amersham Biosciences) to visualize immunoreactive bands. Proteins were detected using antibodies according to manufacturer's instructions. The mouse monoclonal antibody to MAP1LC3B was from NanoTools (Teningen, Germany), the mouse monoclonal $\beta$ actin antibody was from Sigma, and the rabbit polyclonal autophagy cleaved-MAP1LC3A antibody (APG8a) was from Abgent (San Diego, CA).

For immunocytochemical analysis, cells were grown as monolayers on sterile glass chamber slide (Nunc). They were fixed in $-20^{\circ} \mathrm{C}$ cold methanol for 15 minutes, washed three times with PBS, and blocked with 10\% bovine serum in PBS for 30 minutes followed by overnight incubation with primary antibody at $4^{\circ} \mathrm{C}$. Secondary horseradish peroxidise-conjugated (Dako Irc.) antibodies in dilution 1:100 was applied for 50 minutes. DAKO DAB chromogen substrate was applied for approximately 5 minutes until brown staining was observed. The slides were then counterstained with hematoxylin and mounted. Cells were visualized by using an Olympus BX51 microscope with DP70 digital camera. 

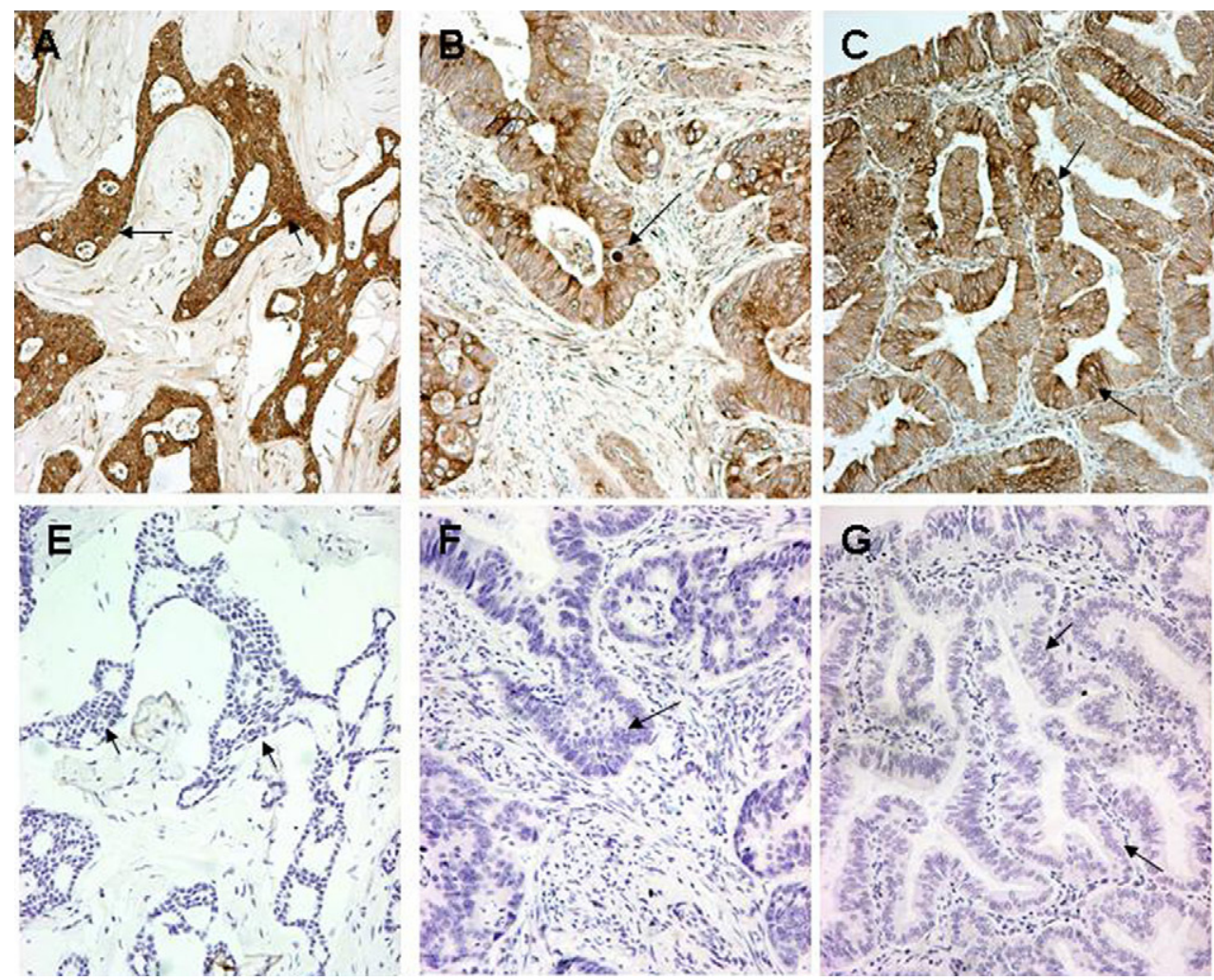

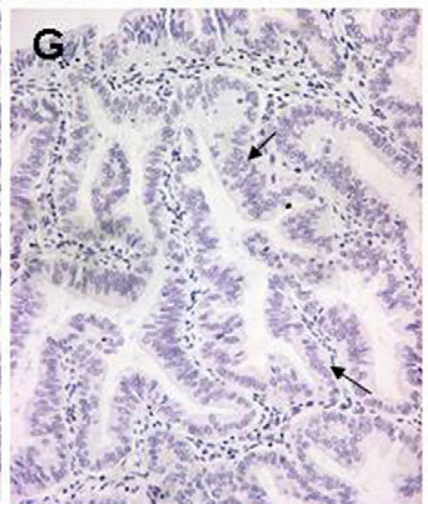

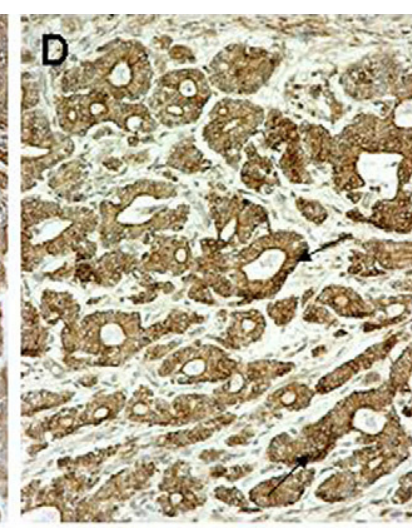
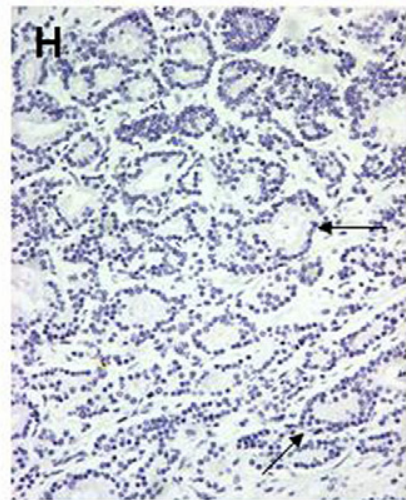

Figure 1. Autophagy in human tissues. Cytoplasmic, perinuclear, and stone-like patterns in malignant breast (A), colonic (B), endometrial (C), and prostatic (D) tissues stained for LC3A. The corresponding negative control sections $(\mathbf{E}-\mathbf{H})$ in the preparation of which the LC3A antibody had been replaced by normal rabbit immunoglobulin-G (Magnification $\times 200$ ). Arrows in $\mathbf{B}, \mathbf{C}$, and $\mathbf{D}$ show stone-like structures and perinuclear staining of LC3A, whereas those in $\mathbf{F}$, $\mathbf{G}$, and $\mathbf{H}$ indicate the corresponding areas in control sections.

\section{Statistical Analysis}

Statistical analysis and graphs were performed using the GraphPad Prism ${ }^{\circledR} 5.0 \kappa \alpha \iota$ Instat $^{\circledR} 3.0$ (GraphPad, San Diego, CA). Interobserver variability was assessed by linear regression analysis. Cancer specific survival curves were plotted using the method of Kaplan and Meier (1958), and the log-rank test was used to determine statistical differences between life tables. A twotailed Fisher exact test and the unpaired two tailed $t$ test was used for testing relationships between categorical tumor variables, as appropriate. Two multivariate models were studied: model 1, which comprised all available variables, and model 2, focusing exclusively on LC3 expression patterns. A Cox proportional hazard model was used to assess the effect of assessed parameters on node metastasis and death events. A $P$ value of $<0.05$ was used for significance.

\section{Results}

\section{MAP1LC3A Antibody Validation}

Validation of MAP1LC3A antibody's specificity (AP1805a, Abgent, San Diego, CA) was accomplished by Western blot analysis of mouse liver extracts. This gave two bands corresponding to the LC3A-I and II proteins (data not shown).

\section{Controls}

All control sections, with omission or substitution of the primary antibody with nonspecific IgG immunoglobulin, showed a complete absence of positive staining (Figure 1, A-H).

\section{LC3A Expression Patterns in Breast Carcinomas}

LC3A protein, as a marker of autophagic activity, was readily detected in all immunohistochemically stained sections of operable breast carcinomas. However, as mentioned earlier, cells expressing LC3A protein showed three distinct autophagic patterns.

\section{The Diffuse Cytoplasmic Pattern}

A diffuse finely/granular reactivity of the cytoplasm (Figure 2A) was noted in many epithelial cells, cancerous and noncancerous, of essentially all sections studied, although to a different extent and staining intensity. Thus, 30/102 tumors in the series were allocated to a high cytoplasmic reactivity for having a strong cytoplasmic LC3A expression in $50 \%$ or more of the cancer cells (Table 2). The remainder (72/102 tumors) was allocated to low cytoplasmic reactivity, as the proportion of LC3A- 


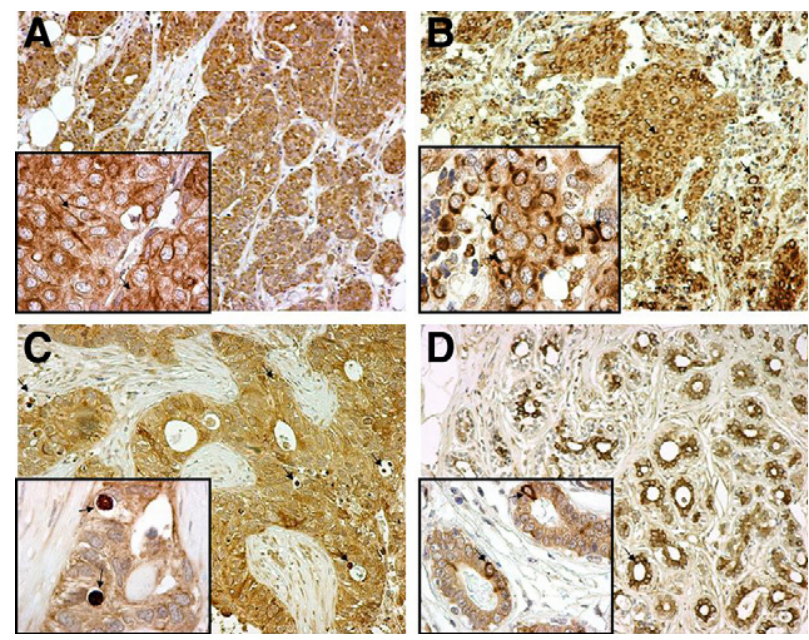

Figure 2. Patterns of LC3A expression in malignant breast tissues and the adjacent "normal" breast epithelium (magnification: large figures $\times 200$, small figures $\times 1000$ ). A: Diffuse cytoplasmic expression of LC3A in breast cancer cells (arrows). B: Juxta-nuclear pattern of LC3A expression in breast cancer cells (arrows). C: Stone-like structures within autophagic vacuoles (arrows) occupying almost the entire cytoplasm of breast cancer cells and pushing the nuclei toward the periphery. D: Nonmalignant "normal" breast glands in the proximity of the tumor with a mixed diffuse cytoplasmic and juxta-nuclear (arrows) LC3A expression.

positive neoplastic cells did not exceed that of $10 \%(0 \%$ to $10 \%)$.

\section{The Cytoplasmic/Juxta-Nuclear Pattern}

Cytoplasmic/Juxta-nuclear staining in the form of crescentic or ring-like perinuclear structures (Figure 2B) was equally discernable and discriminatory. For, indeed, using the 33rd and 66th percentile, the total number of

Table 2. The Relationship of Diffuse Cytoplasmic Pattern with Certain Histopathological and Immunohistochemical Features in Operable Breast Carcinomas

\begin{tabular}{|c|c|c|c|}
\hline Parameter & $\begin{array}{l}\text { Low, } \mathrm{n}(\%) \\
\text { (72 cases) }\end{array}$ & $\begin{array}{l}\text { High, } n(\%) \\
\text { (30 cases) }\end{array}$ & $\begin{array}{c}P \\
\text { value }\end{array}$ \\
\hline \multicolumn{4}{|l|}{ Tumor size } \\
\hline$<1$ & $8(11.1)$ & $6(20.0)$ & \multirow{3}{*}{0.20} \\
\hline 1 to 1.5 & $22(30.6)$ & $12(40.0)$ & \\
\hline 1.6 to 2.0 & $42(58.3)$ & $12(40.0)$ & \\
\hline \multicolumn{4}{|c|}{$\begin{array}{l}\text { Number of positive } \\
\text { nodes }\end{array}$} \\
\hline 0 & $32(44.5)$ & $8(26.7)$ & \multirow{3}{*}{$0.008 *$} \\
\hline 1 to 3 & $16(22.2)$ & $16(53.3)$ & \\
\hline$>3$ & $24(33.3)$ & $6(20.0)$ & \\
\hline \multicolumn{4}{|l|}{ Tumor grade } \\
\hline 1 to 2 & $20(27.8)$ & $14(46.7)$ & \multirow[t]{2}{*}{0.10} \\
\hline 3 & $52(72.2)$ & $16(53.3)$ & \\
\hline \multicolumn{4}{|l|}{ ER } \\
\hline Negative & $34(47.2)$ & $4(13.3)$ & \multirow[t]{2}{*}{0.001} \\
\hline Positive & $38(52.8)$ & $26(86.7)$ & \\
\hline \multicolumn{4}{|l|}{$\mathrm{PgR}$} \\
\hline Negative & $40(55.5)$ & $10(33.3)$ & \multirow[t]{2}{*}{0.05} \\
\hline Positive & $32(44.5)$ & $20(60.7)$ & \\
\hline \multicolumn{4}{|l|}{ c-erbB-2 } \\
\hline Negative & $32(44.4)$ & $16(53.3)$ & \multirow[t]{2}{*}{0.51} \\
\hline Positive & $40(55.6)$ & $14(46.7)$ & \\
\hline
\end{tabular}

${ }^{*} P$ values: 0 versus 1 to $3=0.01 ; 1$ to 3 versus $>3=0.01 ; 0$ versus $>3=0.99$

Negative versus positive $=0.12$ perinuclear structures found in a section was classified into groups of low (0 to 10), intermediate (11 to 50), and high (51 to 172) autophagic activity (Table 3). The longest area occupied by such structures, composed of numerous coarse, rather than fine, granules, was estimated from 7 to $14 \mu \mathrm{m}$ (on average $9 \mu \mathrm{m}$ ).

\section{The "Stone-Like" Pattern}

This was readily recognized as large, rounded, densely stained material, amorphous or laminated, typically enclosed within a cytoplasmic vacuole (Figure $2 \mathrm{C}$ ). The autophagosomes containing such structures varied immensely in size, but usually were large with some of them occupying the whole cytoplasmic area, pushing the nuclei toward the periphery. Thus, the dense rounded LC3A-positive material itself varied in size from 1.2 to 12 $\mu \mathrm{m}$ in diameter, whereas the surrounding vacuole ranged from 1.5 to $22 \mu \mathrm{m}$; they had on average $5 \mu \mathrm{m}$ and $10 \mu \mathrm{m}$ diameter, respectively. The stone-like counts ranged from 1 to 50 per tissue section, and their respective tumors were classified into groups of low (1 to 5 ), intermediate (6 to 12), and high (13 to 50) reactivity, according to the 33rd and 66th percentile and the total number of counts in a section (Table 4).

It should be noted that some of the larger stone-like structures might be spotted at the corresponding H\&E sections when diligently were sought for, but a reliable quantitative assessment of this pattern would definitely require anti-LC3 staining.

\section{LC3A Expression Patterns in Other Carcinomas}

All additional epithelial tumors studied (i.e., human colon, endometrial and prostatic adenocarcinomas) expressed clearly the three LC3 patterns described for breast carcinomas (Figure 1 and data not shown). Omission or replacement of the primary antibody by normal rabbit serum showed a complete absence of reactivity (Figure 1).

\section{Interobserver Variability}

The LC3A autophagic activity, as assessed and scored by light microscopy, was tested for interobserver variation. Using a linear regression analysis the scores given by the two pathologists (E.S. and A.G.) had an excellent correlation for all three immunohistochemical expression patterns suggesting that these are easily recognized and reliably scored. The correlation coefficient $r$-value and the significance of correlation $P$ value were $0.94 /$ $<0.001$ for the diffuse cytoplasmic expression, 0.96/ $P<0.001$ for the perinuclear/crescentic pattern, and $0.97 /<0.001$ for the stone-like pattern.

\section{Histopathological Correlations}

The diffuse cytoplasmic pattern, when strong and extensive, was correlated with high ER and PgR expression 
Table 3. The Relationship of Crescentic/Perinuclear Pattern with Certain Histopathological and Immunohistochemical Features in Operable Breast Carcinomas

\begin{tabular}{|c|c|c|c|c|}
\hline Parameter & $\begin{array}{l}\text { Low, } \mathrm{n}(\%) \\
\text { (34 cases) }\end{array}$ & $\begin{array}{l}\text { Intermediate, } \mathrm{n}(\%) \\
\quad \text { (34 cases) }\end{array}$ & $\begin{array}{l}\text { High, n (\%) } \\
\text { (34 cases) }\end{array}$ & $P$ value \\
\hline \multicolumn{5}{|l|}{ Tumor size } \\
\hline$<1$ & $8(23.6)$ & $2(5.9)$ & $4(11.8)$ & \multirow{3}{*}{$<0.0001$} \\
\hline 1 to 1.5 & $6(17.6)$ & $9(26.5)$ & $19(55.9)$ & \\
\hline 1.6 to 2.0 & $20(58.8)$ & $23(67.6)$ & $11(32.3)$ & \\
\hline \multicolumn{5}{|c|}{ Number of positive nodes } \\
\hline 0 & $12(35.3)$ & $15(44.1)$ & $13(38.2)$ & \multirow{3}{*}{$0.31^{*}$} \\
\hline 1 to 3 & $8(23.5)$ & $10(29.4)$ & $14(41.2)$ & \\
\hline$>3$ & $14(41.2)$ & $9(26.5)$ & $7(20.6)$ & \\
\hline \multicolumn{5}{|l|}{ Tumor grade } \\
\hline 1 to 2 & $8(23.5)$ & $14(41.2)$ & $12(35.3)$ & \multirow[t]{2}{*}{0.29} \\
\hline 3 & $26(76.5)$ & $20(58.8)$ & $22(64.7)$ & \\
\hline \multicolumn{5}{|l|}{ ER } \\
\hline Negative & $22(64.7)$ & $12(35.3)$ & $4(11.8)$ & \multirow[t]{2}{*}{$<0.0001$} \\
\hline \multirow{2}{*}{\multicolumn{5}{|c|}{ PgR }} \\
\hline & & & & \\
\hline Negative & $32(94.1)$ & $14(41.2)$ & $4(11.8)$ & \multirow[t]{2}{*}{$<0.0001$} \\
\hline Positive & $2(5.9)$ & $20(58.8)$ & $30(88.2)$ & \\
\hline \multicolumn{5}{|l|}{ c-erbB-2 } \\
\hline Negative & $14(41.2)$ & 19 (55.9) & $15(44.1)$ & \multirow[t]{2}{*}{0.43} \\
\hline Positive & $20(58.8)$ & $15(44.1)$ & $19(55.9)$ & \\
\hline
\end{tabular}

${ }^{*} P$ values: 0 versus 1 to $3=0.61 ; 1$ to 3 versus $>3=0.13 ; 0$ versus $>3=0.35$.

Negative versus positive $=0.74$

$(P=0.001$ and $P=0.05$, respectively), but also with metastatic involvement of $1-3$ axillary lymph nodes $(P=$ 0.008; Table 2).

A juxta-nuclear pattern of more than 50 tumor cells per section showed a similar, albeit stronger, association with ER $(P<0.0001)$ and PgR $(P<0.0001)$, and an inverse association with tumor size $(P=0.0001$; Table 3$)$. No association was noted between such crescentic/perinuclear staining and tumor differentiation, number of lymph nodes involved, or c-erbB-2 reactivity.

An exaggerated number of stone-like structures (13 to 50 positive tumor cells per section) was correlated directly with breast carcinomas of poor differentiation $(P=$
0.005), and inversely with ER expression ( $P=0.01$; Table 4). No apparent association with tumor size, nodal disease, PgR, or c-erbB-2 status was noted.

\section{Correlation Among the LCBA Immunohistochemical Patterns}

This is shown in Table 5. There was a direct association between the diffuse cytoplasmic and the cytoplasmic/ juxta-nuclear pattern $(P=0.006)$, and an inverse relationship of the stone-like pattern with those of the diffuse

Table 4. The Relationship of "Stone-Like" Structures with Certain Histopathological and Immunohistochemical Features in Operable Breast Carcinomas

\begin{tabular}{|c|c|c|c|c|}
\hline Parameter & $\begin{array}{l}\text { Low, n }(\%) \\
\text { (34 cases) }\end{array}$ & $\begin{array}{l}\text { Intermediate, } \mathrm{n}(\%) \\
\quad \text { (36 cases) }\end{array}$ & $\begin{array}{l}\text { High, } n(\%) \\
\text { (32 cases) }\end{array}$ & $P$ value \\
\hline \multicolumn{5}{|l|}{ Tumor size } \\
\hline$<1$ & $6(17.6)$ & $2(5.6)$ & $6(18.7)$ & \multirow{3}{*}{0.28} \\
\hline 1 to 1.5 & $10(29.4)$ & $16(44.4)$ & $8(25.0)$ & \\
\hline 1.6 to 2.0 & 18 (53.0) & $18(50.0)$ & 18 (56.3) & \\
\hline \multicolumn{5}{|c|}{ Number of positive nodes } \\
\hline 0 & $14(41.2)$ & $14(38.9)$ & $12(37.5)$ & \multirow{3}{*}{0.76} \\
\hline 1 to 3 & $12(35.3)$ & $12(33.3)$ & $8(25.0)$ & \\
\hline$>3$ & $8(23.5)$ & $10(27.8)$ & $12(37.5)$ & \\
\hline \multicolumn{5}{|l|}{ Tumor grade } \\
\hline 1 to 2 & $18(53.0)$ & $6(16.7)$ & $10(31.2)$ & \multirow[t]{2}{*}{0.005} \\
\hline 3 & $16(47.0)$ & $30(83.3)$ & $22(68.8)$ & \\
\hline \multicolumn{5}{|l|}{ ER } \\
\hline Negative & $8(23.5)$ & $12(33.3)$ & $18(56.3)$ & \multirow[t]{2}{*}{0.01} \\
\hline Positive & $26(76.5)$ & $24(66.7)$ & $14(43.7)$ & \\
\hline \multicolumn{5}{|l|}{ PgR } \\
\hline Negative & $12(35.3)$ & $18(50.0)$ & $20(62.5)$ & \multirow{2}{*}{0.08} \\
\hline Positive & $22(64.7)$ & $18(50.0)$ & $12(37.5)$ & \\
\hline \multicolumn{5}{|l|}{ c-erbB-2 } \\
\hline Negative & $20(58.8)$ & $16(44.4)$ & $12(37.5)$ & \multirow[t]{2}{*}{0.20} \\
\hline Positive & $14(41.2)$ & $20(55.6)$ & $20(62.5)$ & \\
\hline
\end{tabular}


Table 5. The Relationship between Different LC3A Immunohistochemical Patterns in Operable Breast Carcinomas

\begin{tabular}{|c|c|c|c|c|c|c|c|}
\hline \multirow[b]{2}{*}{ Pattern } & \multicolumn{3}{|c|}{ Diffuse cytoplasmic } & \multicolumn{3}{|c|}{ Stone-like } & \multirow[b]{2}{*}{$P$ value } \\
\hline & Low & High & $P$ value & Low & Intermediate & High & \\
\hline \multicolumn{8}{|c|}{ Crescentic/perinuclear } \\
\hline Low & 30 & 4 & 0.006 & 8 & 12 & 14 & 0.10 \\
\hline Intermediate & 24 & 10 & $0.01^{*}$ & 12 & 9 & 13 & $0.01^{*}$ \\
\hline High & 18 & 16 & & 14 & 15 & 5 & \\
\hline \multicolumn{8}{|l|}{ Stone-like } \\
\hline Low & 18 & 16 & 0.008 & & & & \\
\hline Intermediate & 26 & 10 & $0.01^{*}$ & & & & \\
\hline High & 28 & 4 & & & & & \\
\hline
\end{tabular}

*Low/intermediate versus high for both crescentic/perinuclear and stone-like patterns.

cytoplasmic $(P=0.008)$ and the cytoplasmic/juxta-nuclear $(P=0.03)$.

\section{LC3A Expression in Non-Neoplastic Tissues Adjacent to Breast Tumors}

The diffuse cytoplasmic LC3A staining was consistently seen in the adjacent, non-neoplastic breast lobules and ducts of the eleven cases studied, whereas the crescentic/perinuclear pattern was observed in an appreciable number of cells (Figure 2D). By contrast, stonelike structures were not seen in the noncancerous breast epithelium.

\section{LC3A Expression Patterns in Spheroids and Xenografts}

The typical LC3A patterns of diffuse cytoplasmic, juxtanuclear (in crescentic or perinuclear form) and stone-like were confirmed in MDA231 xenograft sections (Figure 3, $\mathrm{A}$ and $\mathrm{B}$ ). Of interest, stone-like structures were frequently seen in areas invading the adjacent tissues. Similarly, all three patterns of autophagy were recognized in HCT116 tumor spheroids (Figure 3, C-F).

\section{Electron Microscopy}

Ultrastructural investigation of tumor spheroids confirmed the presence of large dense, rounded, amorphous material representing the 'stone-like' structures (Figure 4, A-D). Vacuoles containing masses of membranous debris within tightly fitting vacuoles in the cell cytoplasm were readily identified.

\section{Cell Line Immunocytochemistry and Immunoblotting}

Immunocytochemical investigation revealed that both LC3A and LC3B were expressed in the cytoplasm of cancer cells, with a prominence of the perinuclear pattern, after exposure to anoxia and Thapsigargin (Figure 5). Immunoblot analysis showed up-regulation of LC3A, LC3BI, and LC3BII after exposure of cancer cells to anoxia and Thapsigargin (Figure 6. See also supplemental Figure S1 at $h$ ttp://ajp.amjpathol.org).

\section{Survival Analysis}

Kaplan-Meier cancer-specific survival curves, plotted according to LC3A patterns, are indicated in Figures 7 , A-C. A diffuse cytoplasmic pattern expressing more than $50 \%$ of cancer cells had a similar survival rate with that of low cytoplasmic reactivity (Figure 7A). Yet, patients having breast tumors with high and intermediate numbers of juxta-nuclear structures experienced a favorable 20-year survival compared with those with similar patterns of low autophagic activity $(P=0.005$; Figure 7B). By contrast, the high presence of stone-like structures was correlated with a less favorable long term clinical outcome $(P=$ 0.0002; Figure 7C).

Other parameters which linked with prognosis included: an increased number of metastatic lymph nodes $(P<$
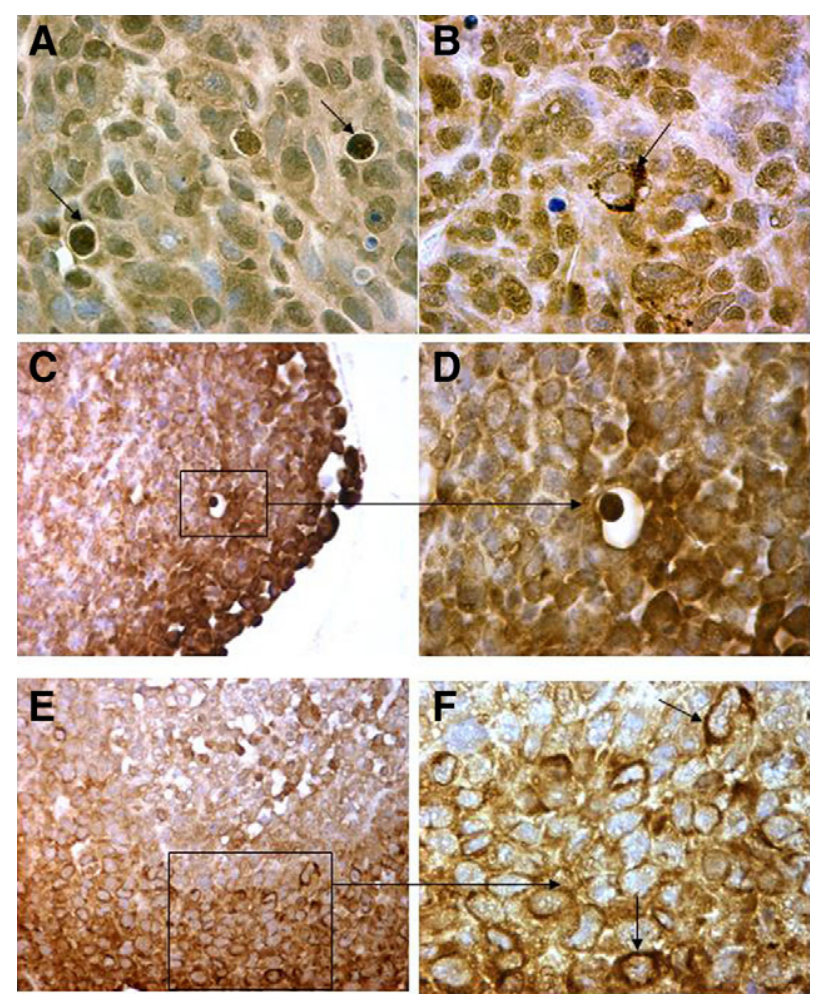

Figure 3. Immunohistochemical figures from MDA231 human breast tumor xenografts (A and B: magnification $\times 400)$ and HCT116 colon tumor spheroids $(\mathbf{C}$ and $\mathbf{D}$ : magnification $\times 200$, and $\mathbf{E}$ and $\mathbf{F}$ : magnification $\times 400$ ) showing the three distinct patterns of LC3A expression (arrows). 

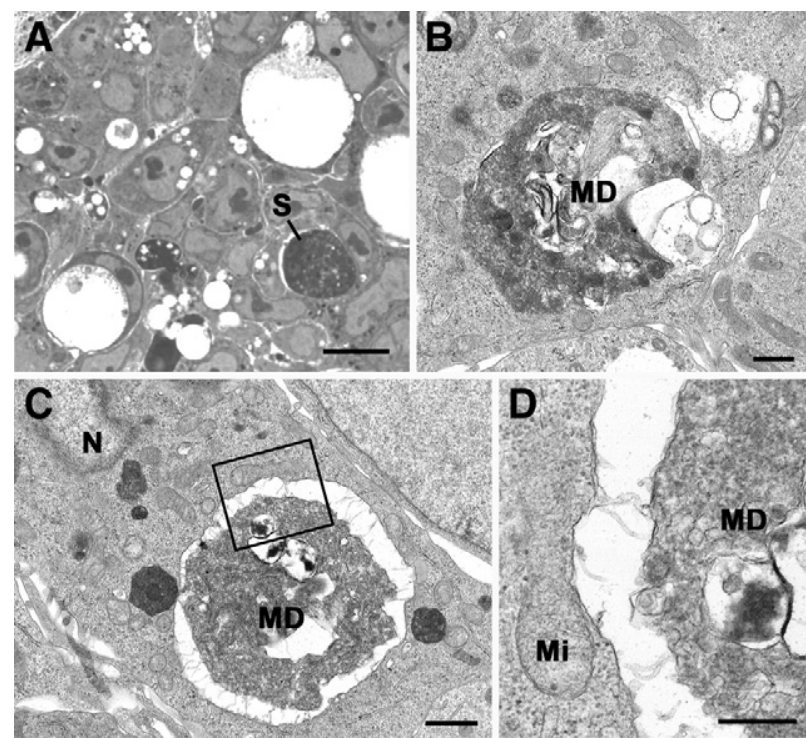

Figure 4. Light (A) and electron (B-D) micrographs of a section through a HCT116 tumor spheroid. A: Section showing tightly packed cells, many of which contain lucent vacuoles of various sizes. Note the cell with a large dense rounded material representing a stone-like structure (S). Scale bar is 10 $\mu \mathrm{m}$. Plastic section/Azure A stained. B: Electron micrograph showing a small vacuole containing a mass of membranous debris (MD) within a tightly fitting vacuole in the cell cytoplasm. Scale bar is $0.5 \mu \mathrm{m}$. C: Low-power electron micrograph of a stone-like structure similar to that in $\mathbf{A}$ showing it to consist of a large mass of degenerating material (MD) within the cell cytoplasm. N indicates nucleus. Scale bar is $1 \mu \mathrm{m}$. D: Detail of the enclosed area in $\mathbf{C}$ showing the central mass to consist of a mass of MD slightly separated from the vacuolar membrane. Mi indicates mitochondrion. Scale bar is $0.5 \mu \mathrm{m}$.

$0.0001)$, and lack of ER $(P=0.001)$ or PgR expression $(P<0.0001$; data not shown).

In a multivariate analysis of cancer-related death events, comprising all histopathological and autophagic features (Table 6, model 1), the number of lymph nodes with metastatic deposits and the presence of stone-like structures were the only variables having an independent prognostic value (t ratio 4.93, $P<0.0001$ and $\mathrm{t}$ ratio $=$ $2.13, P=0.03$, respectively). In another model, examining the impact of the autophagic patterns on death

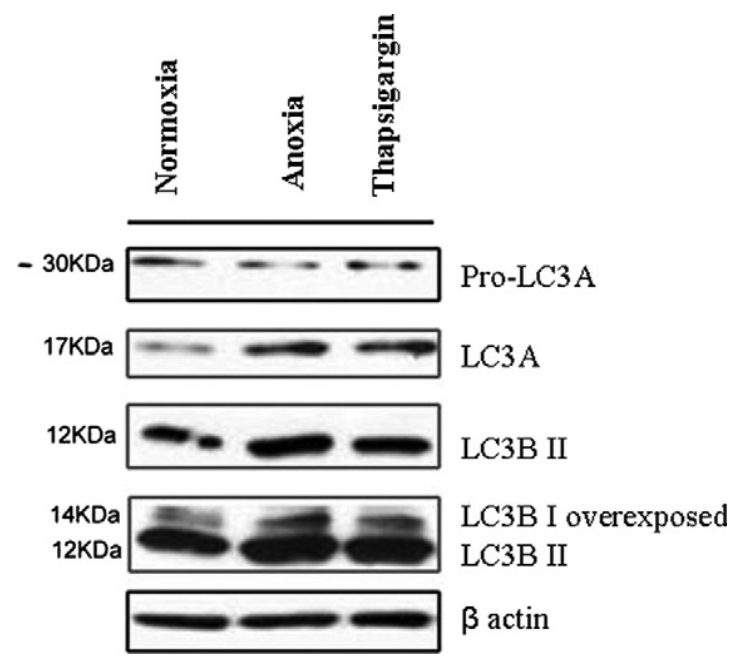

Figure 6. Induction of LC3A and LC3B in MCF-7 breast cancer cells. MCF- 7 cells were treated: under anoxia for 48 hours, with Thapsigargin $(300 \mathrm{nmol} / \mathrm{L})$ and incubated under normoxic conditions for 24 hours. Levels of protein expression were measured by immunoblot analysis using antibodies against LC3A, LC3B, and $\beta$ actin.

events excluding all other variables (Table 6, model 2), an independent association was noted between an increased number of stone-like structures and poor survival (t ratio 2.31, $P$ value 0.02), and between limited number of juxta-nuclear structures and unfavorable survival (t ratio $3.73, P$ value 0.0003 ).

\section{Discussion}

During tumor growth, hypoxia, and nutrient deprivation cannot be tolerated unless there is neoangiogenesis and a shifting from oxidative phosphorylation to anaerobic glycolysis- "the Warburg effect."27,28,34-37 Complementary mechanisms include activation of antiapoptotic pathways $^{16,17}$ and autophagy - a self-degradation mechanism by which energy is produced by recycling long-
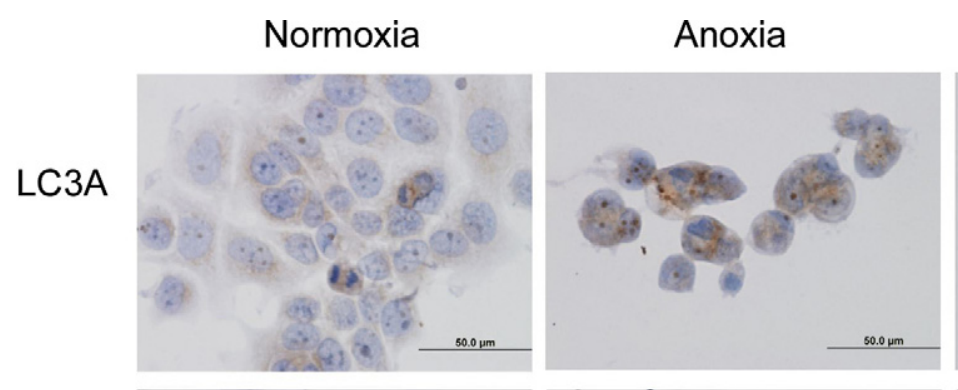

\section{Thapsigargin}
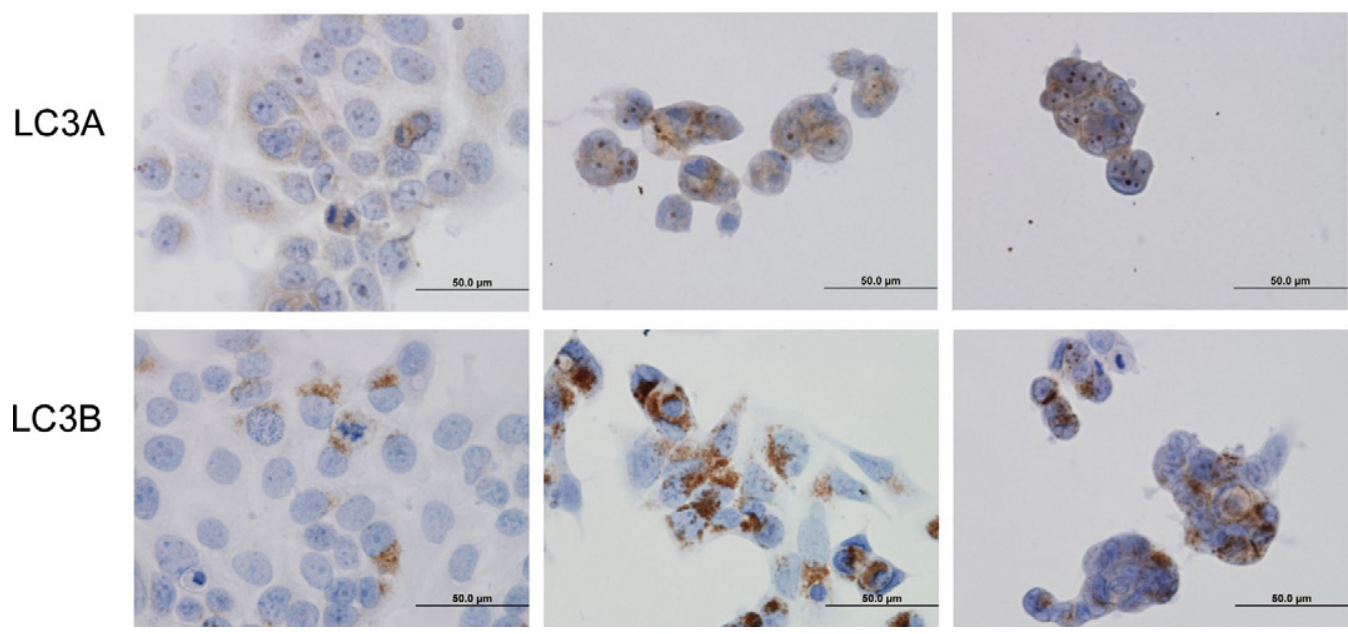

Figure 5. Staining of LC3A and LC3B in MCF7 breast cancer cells treated: under normoxia, under anoxia for 48 hours, with Thapsigargin (300 nmol/L) for 24 hours. 

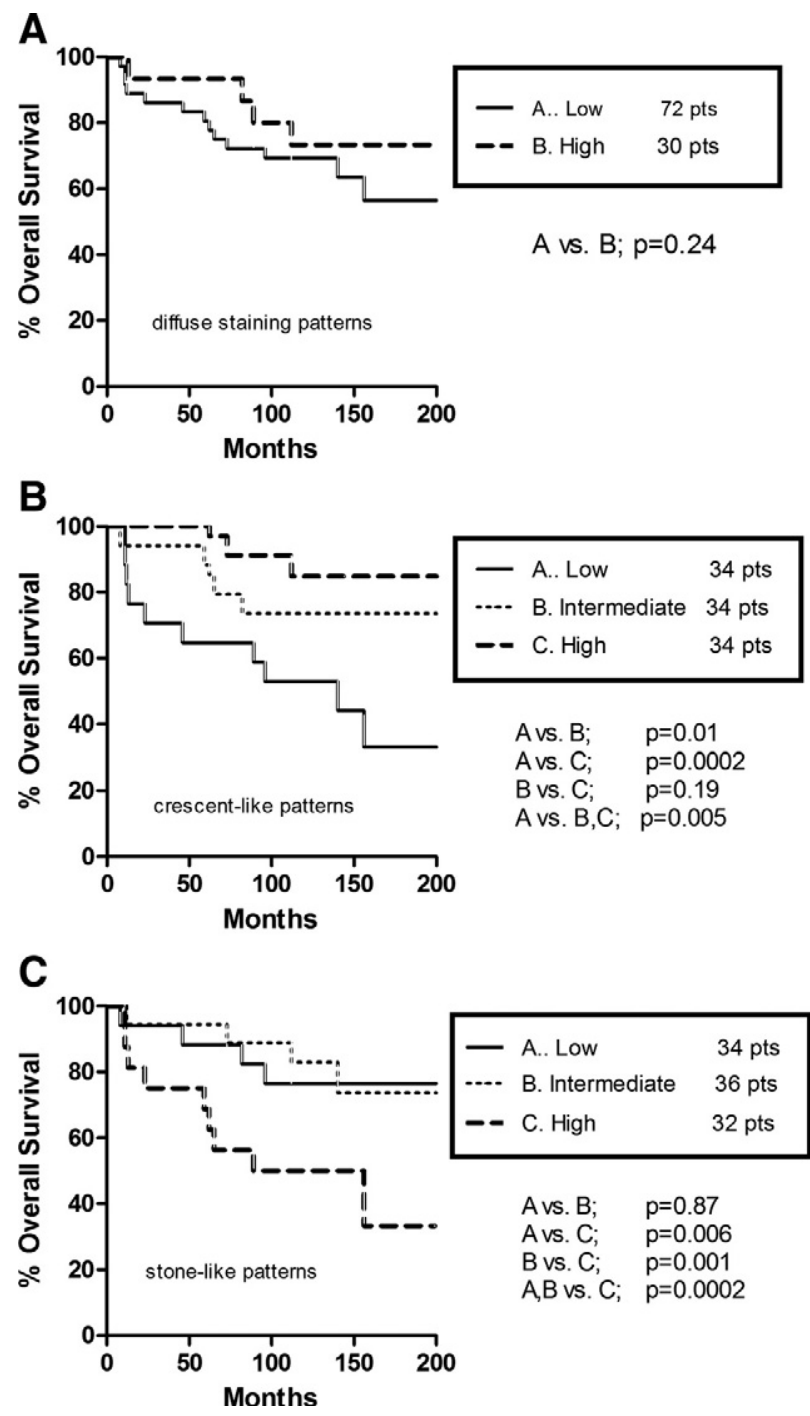

Figure 7. Seventeen-year cancer-specific survival rates in patients with operable breast carcinomas: diffuse cytoplasmic pattern (A), juxta-nuclear (crescentic/perinuclear) pattern (B), and "stone-like" pattern (C).

lived proteins and organelles. ${ }^{7,8}$ This is accomplished by disposing of cytoplasmic components, including excess or defective organelles, to the lysosomes. ${ }^{38}$

Cells, therefore, use autophagy as an adaptation mechanism to various stresses, mainly starvation and oxygen deprivation. There are four main forms of autophagy in mammalian cells: macroautophagy, microautophagy, chaperone-mediated autophagy, and the crinophagy. ${ }^{39}$ More recently, mitophagy has been recognized as a distinct process of macroautophagy. ${ }^{40}$ Among them, macroautophagy was thought to be responsible for the majority of the intracellular protein degradation, particularly the starvationinduced proteolysis. ${ }^{8,41}$ In macroautophagy (simply called "autophagy" hereafter), the main morphological features are the isolation membranes-single-membrane cupshaped structures, and the autophagic vesicles (autophagosomes/autolysosomes) - sequestration of cargo within double membrane cytoplasmic vesicles. ${ }^{38}$ However, under certain conditions, autophagy may be excessively triggered resulting in incomplete degradation of cellular components and aggregation of damaged organelles rearranged in the form of "membranous whorls" or "myelin figures"18-20_a process that may lead to massive destruction of tumor cells.

Transmission electron microscopy remains the standard method for investigating autophagy in tissue sections. ${ }^{18,42}$ Nonetheless, misinterpretation of various electron microscopic images as autophagic vacuoles is frequent, leading to erroneous results. ${ }^{18,42}$ Immunoelectron microscopy, using antibodies against autophagosomal markers, improved the detection of autophagic structures $^{8,18}$ but is a method requiring specifically-trained personnel and expensive equipment. ${ }^{42}$ Fluorescence microscopy, on the other hand, is accompanied by excessive fluorescent background making recognition of autophagosomes almost impossible. ${ }^{28,42,43}$ Recently, the antibodies LC3A and Beclin-1 have been introduced into laboratory practice disclosing autophagic activity under light microscopy.

In this study, the reactivity of LC3A with mammary tumor cells enabled us to detect several distinct patterns of autophagy: the diffuse cytoplasmic, the juxta-nuclear (crescentic/perinuclear), and the "stone-like" pattern. They were all readily detected by light microscopy, with only minimal interobserver variation. Interestingly, these very patterns of LC3A expression were observed in HCT116 colon cancer spheroids and MDA231 xenografts, after immunohistochemical analysis. Furthermore, a prominent perinuclear pattern was made out in cell line immunocytochemistry, whereas immunoblotting disclosed induction of LC3A and LC3B after anoxia or endoplasmic reticulum stress, and electron microscopy reaffirmed the presence of stone-like structures. These would imply that reduced oxygen tension is a principal cause of autophagy activity in breast cancer cells. It is of note that among the 25 or more Atg proteins that take part in the autophagic response ${ }^{33,39-42}$ only LC3 in all three isoforms ( $A, B$, and $C$ ) is known to reside specifically in the autophagosomal/autolysosomal membranes $^{8,18,27,28,44}$ and the isolation membrane-the site of Atg protein accumulation ${ }^{44-47}$ and the organizing center for vesicle formation. ${ }^{48}$

In this context, it has been postulated recently that the number of autophagosomes detected in tissues can be used as a measure of autophagic activity. ${ }^{49}$ However, despite an exponential growth in the number of publications on the subject, the role of autophagy in cancer progression remains controversial. ${ }^{50-58}$ Some data favor the idea that autophagy suppresses tumor growth, whereas other indicate that autophagy promotes tumor development by protecting tumor cells from cell death stimuli. ${ }^{50-58}$ This is confounded by the lack of application of uniform methodology and criteria of reactivity.

An early report on breast carcinomas by Liang et al (1999) showed a loss of Beclin-1 expression in 56\% of tumors compared with normal breast epithelium, ${ }^{59}$ and correlated with decreased expression of this protein and a loss of tumor suppressor functions in cancer cells. Miracco et al (2007), ${ }^{60}$ using the same antibody at a dilution of $1: 50$ in 212 cerebral tumors, found that a decreased expression of Beclin-1, mainly in astrocytic tumors and meningiomas, was related to the aggressiveness of brain tumors. ${ }^{54}$ However, Ahn et $\mathrm{al}^{53}$ noted an 
Table 6. Multivariate Analysis of Death Events in Operable Breast Carcinomas

\begin{tabular}{|c|c|c|c|c|c|c|}
\hline \multirow[b]{2}{*}{ Parameter } & \multicolumn{3}{|c|}{ Model 1} & \multicolumn{3}{|c|}{ Model 2} \\
\hline & Odds & $95 \% \mathrm{Cl}$ & $P$ value & Odds & $95 \% \mathrm{Cl}$ & $P$ value \\
\hline $\begin{array}{l}\text { Tumor size } \\
\qquad(>1.6 \mathrm{~cm})\end{array}$ & 0.51 & 0.2 to 1.2 & 0.60 & - & - & - \\
\hline Tumor grade & & & & & & \\
\hline $\begin{array}{l}\text { (3) } \\
\text { Number of positive nodes }\end{array}$ & 1.26 & 0.7 to 2.6 & 0.20 & - & - & - \\
\hline $\mathrm{ER}^{(>3 \text { nodes })}$ & 4.93 & 2.2 to 9.8 & $<0.0001$ & - & - & - \\
\hline $\begin{array}{l}\text { (negative) } \\
\text { PgR }\end{array}$ & 1.27 & 0.6 to 2.6 & 0.20 & - & - & - \\
\hline $\begin{array}{l}\text { (negative) } \\
\text { c-erbB-2 }\end{array}$ & 1.46 & 0.7 to 3.1 & 0.14 & - & - & - \\
\hline $\begin{array}{c}\text { (positive) } \\
\text { LC3A diffuse }\end{array}$ & 1.46 & 0.7 to 3.2 & 0.14 & - & - & - \\
\hline $\begin{array}{l}\text { (low) } \\
\text { LC3A juxta-nuclear }\end{array}$ & 0.42 & 0.2 to 1.1 & 0.67 & 0.91 & 0.4 to 2.1 & 0.36 \\
\hline $\begin{array}{l}\text { (low) } \\
\text { LC3A stone-like }\end{array}$ & 1.07 & 0.6 to 1.7 & 0.28 & 3.73 & 1.6 to 9.3 & 0.0003 \\
\hline (high) & 2.13 & 1.2 to 5.1 & 0.03 & 2.31 & 1.7 to 5.9 & 0.02 \\
\hline
\end{tabular}

—, excluded parameters in Model 2.

increased expression of Beclin-1 in colorectal and gastric carcinomas, compared with their normal counterparts. The antibody was used at a dilution of 1:200 in tissue microarray slides (comprising 103 colorectal and 60 gastric carcinomas) rather than whole tissue sections. The authors suggested that neoexpression of Beclin-1 may play a role in colorectal and gastric tumorigenesis. ${ }^{53} \mathrm{An}$ increased staining intensity with Beclin-1 was also reported in malignant prostatic tissues, relative to normal prostates, by DiPaola et al (2008). ${ }^{61}$ These authors used tissue microarray immunohistochemistry with the primary antibody at a dilution of 1:240. DiPaola and associates concluded that normal and tumor cells require the catabolic process of autophagy to survive nutrient deprivation. ${ }^{61}$ Others, like Fujii et al (2008), correlated a high autophagic reactivity at the peripheral areas of pancreatic tumors with poor overall survival and shorter diseasefree periods. ${ }^{26}$ There was also a relationship with tumor size and tumor necrosis. This study used anti-LC3A antibody at 1:50 dilution on whole tissue sections and included 71 cases. LC3A expression was not noted in the noncancerous epithelium. ${ }^{26}$

In our study, both the diffuse cytoplasmic and the cytoplasmic/juxta-nuclear patterns, when of high LC3A reactivity, were associated with increased $\mathrm{ER}$ and $\mathrm{PgR}$ expression-a favorable prognostic factor, although only the juxta-nuclear pattern showed an inverse association with tumor size and a favorable overall prognosis. This is probably because the diffuse cytoplasmic staining, a possible result of reactivity with the soluble LC3A-I form, was also correlated, rather unexpectedly, with metastases to 1 to 3 axillary lymph nodes-an adverse prognostic factor that we are unable to explain. The stone-like pattern, on the other hand, which may mark completion of the autophagic process, was directly related to high grade tumors and inversely to ER-a combined loss of tumor differentiation and hormone receptor expression that may be interpreted as an indication of aggressiveness. In fact, a high autophagic activity in the form of stone-like structures was associated with decreased long term survival.

It appears that the granular staining of the cytoplasm, either fine and diffuse or somewhat coarser and juxtanuclear, is a result of reactivity with the soluble form of the LC3A antibody representing autophagy-related (Atg) proteins that are essential for the "physiological" degradative function of autophagy. ${ }^{46}$ This is further supported by the fact that such patterns are often seen in nonneoplastic breast tissues residing at the proximity of cancer, whereas the tumors themselves were associated with ER, PgR expression, and good prognosis. With regard to the stone-like structures, these, probably being an important feature of malignant tissues, were thought to appear under conditions of extreme stress (ie, when increased autophagic stimulation may lead to overload of degenerative cytoplasmic components, exhaustion of enzymes or lysosomal enzyme defects, and, ultimately, accumulation of debris and massive destruction of tumor cells). Indeed, stone-like structures appear to reflect an excessive autophagic response - an apparent consequence of a massive degradation of cellular components, which has been variously called "membranous whorls" or "myelin figures"18-20,62,63 and were correlated inversely with ER expression and directly with high grade tumors and aggressive tumor behavior.

This dichotomy of biological behavior does not appear unreasonable as the crescentic/perinuclear pattern, composed of autophagosomes of relatively small size, seems to reflect a relatively low tumor cell turnover with an intact autophagic machinery, which is beneficial for both malignant and nonmalignant/stressed "normal" cells suffering from varying degrees of acidosis. In contrast, the stone-like structures, being of large size and occurring in the most rapidly proliferating malignant breast tissues, are related to a high tumor cell turnover, an increased degradative process and an aggressive tumor behavior. ${ }^{64}$ This view, often called a "context dependent autophagy," ${ }^{65}$ is consistent with experimental evidence supporting 
a role in both cancer suppression and development. ${ }^{26}$ Thus, low levels of autophagy promote the survival of normal and tumor cells during nutrient starvation, whereas excessive levels of this phenomenon promote cell death presumably via self-cannibalization. ${ }^{26}$

These observations on operable breast carcinomas seem to indicate that a physiological autophagic response occurring in a breast tumor is revealing of a phenotype of low malignant potential. An abnormal autophagic response, on the other hand, may simply reflect tumor aggressiveness - a rapidly growing tumor that survives the conditions of intense oxygen and nutrient exhaustion (caused by the unlimited proliferating cells) by turning on to an over-activated autophagic state expressed as stone-like structures. Nevertheless, the possibility of a specific cancer cell abnormality affecting the autophagic/lysosomal machinery per se and influencing directly cancer growth and metastasis cannot be excluded.

\section{Conclusions}

Two points of interest emerged from this study. First, it was shown that the LC3A protein, a marker of autophagic activity, can be readily detected by light microscopy in breast carcinomas. Second, the juxta-nuclear pattern of autophagy, common in both neoplastic and non-neoplastic breast tissues, was statistically correlated with a more favorable outcome, whereas the stone-like pattern, an apparently important finding of malignant tumors, was linked with a less favorable prognosis. Whether the presence of such vacuole enclosed stone-like structures reflect an abnormally regulated or responding autophagic machinery is open to question. More work is certainly needed before the prognostic and predictive value of the autophagic patterns described in breast carcinomas is fully appreciated.

\section{References}

1. Giatromanolaki A, Sivridis E, Koukourakis MI: Tumour angiogenesis: vascular growth and survival. APMIS 2004, 112:431-440

2. Jain RK: Molecular regulation of vessel maturation. Nat Med 2003, 9:685-693

3. Vaupel $P$, Thews $O$, Hoeckel M: Treatment resistance of solid tumors: role of hypoxia and anemia. Med Oncol 2001, 18:243-259

4. Harris AL: Hypoxia-a key regulatory factor in tumour growth. Nat Rev Cancer 2002, 2:38-47

5. Izuishi K, Kato K, Ogura T, Kinoshita T, Esumi H: Remarkable tolerance of tumor cells to nutrient deprivation: possible new biochemical target for cancer therapy. Cancer Res 2000, 60:6201-6207

6. Esumi H, Izuishi K, Kato K, Hashimoto K, Kurashima Y, Kishimoto A, Ogura T, Ozawa T: Hypoxia and nitric oxide treatment confer tolerance to glucose starvation in a 5.-AMP-activated protein kinasedependent manner. J Biol Chem 2002, 277:32 791-798

7. Shintani T, Klionsky DJ: Autophagy in health and disease: a doubleedged sword. Science 2004, 306:990-995

8. Mizushima N, Ohsumi Y, Yoshimori T: Autophagosome formation in mammalian cells. Cell Struct Funct 2002, 27:421-429

9. Yorimitsu T, Klionsky DJ: Autophagy: molecular machinery for self eating. Cell Death Differ 2005, 12:1542-1552

10. Locopo N, Fanelli M, Gasparini G: Clinical significance of angiogenic factors in breast cancer. Breast Cancer Res Treat 1998, 52:159-173

11. Giatromanolaki A, Harris AL: Tumour hypoxia, hypoxia signaling path- ways and hypoxia inducible factor expression in human cancer. Anticancer Res 2001, 21:4317-4324

12. Koukourakis MI, Manolas C, Minopoulos G, Giatromanolaki A, Sivridis $\mathrm{E}$ : Angiogenesis relates to estrogen receptor negativity, c-erbB-2 overexpression and early relapse in node-negative ductal carcinoma of the breast. Int J Surg Pathol 2003, 11:29-34

13. Giatromanolaki A, Sivridis E, Simopoulos C, Polychronidis A, Gatter KC, Harris AL, Koukourakis MI: Differential assessment of angiogenic activity and of vascular survival ability (VSA) in breast cancer. Clin Exp Metastasis 2002, 19:673-679

14. Airley RE, Mobasheri A: Hypoxic regulation of glucose transport, anaerobic metabolism and angiogenesis in cancer: novel pathways and targets for anticancer therapeutics. Chemotherapy 2007, 53:233-256

15. Koukourakis MI, Pitiakoudis M, Giatromanolaki A, Tsarouha A, Polychronidis A, Sivridis E, Simopoulos C: Oxygen and glucose consumption in gastrointestinal adenocarcinomas: correlation with markers of hypoxia, acidity and anaerobic glycolysis. Cancer Sci 2006 97:1056-1060

16. Bursch W, Ellinger A, Gerner C, Fröhwein U, Schulte-Hermann R: Programmed cell death (PCD). Apoptosis, autophagic PCD, or others? Ann N Y Acad Sci 2000, 926:1-12

17. Viktorsson K, Lewensohn R, Zhivotovsky B: Apoptotic pathways and therapy resistance in human malignancies. Adv Cancer Res 2005, 94:143-196

18. Martinet W, De Meyer GRY, Andries L, Herman AG, Kockx MM: In situ detection of starvation-induced autophagy. J Histochem Cytochem 2006, 54:85-96

19. Bhattacharyya TK, Buttler DG: Ultrastructure of the adrenocortical homologue in dexamethasone-treated eels. J Anat 1980, 130:323-332

20. Fedorko M: Effect of chloroquine on morphology of cytoplasmic granules in maturing human leukocytes - an ultrastructural study. J Clin Investigation 1967, 12:1932-1942

21. Hickman S, Neufeld EF: A hypothesis for I-cell disease: defective hydrolases that do not enter lysosomes. Biochem Biophys Res Comm 1972, 49:992-999

22. Zhong H, De Marzo AM, Laughner E, Lim M, Hilton DA, Zagzag D, Buechler P, Isaacs WB, Semenza GL, Simons JW: Overexpression of hypoxia-inducible factor 1alpha in common human cancers and their metastases. Cancer Res 1999, 59:5830-5835

23. Koong AC, Mehta VK, Le QT, Fisher GA, Terris DJ, Brown JM Bastidas AJ, Vierra M: Pancreatic tumors show high levels of hypoxia. Int J Radiat Oncol Biol Phys 2000, 48:919-922

24. Buchler P, Reber HA, Lavey RS, Tomlinson J, Büchler MW, Friess $H$ Hines OJ: Tumor hypoxia correlates with metastatic tumor growth of pancreatic cancer in an orthotopic murine model. J Surg Res 2004, 120:295-303

25. Kumar R, Vadlamudi RK, Adam L: Apoptosis in mammary gland and cancer. Endocr Relat Cancer 2000, 7:257-269

26. Fujii S, Mitsunaga S, Yamazaki M, Hasebe T, Ishii G, Kojima M, Kinoshita T, Ueno T, Esumi H, Ochiai A: Autophagy is activated in pancreatic cancer cells and correlates with poor patient outcome. Cancer Sci 2008, 99:1813-1819

27. He H, Dang Y, Dai F, Guo Z, Wu J, She X, Pei Y, Chen Y, Ling W, Wu C, Zhao S, Liu JO, Yu L: Post-translational modifications of three members of the human MAP1LC3 family and detection of a novel type of modification for MAP1LC3B. J Biol Chem 2003, 278:29278-29287

28. Kabeya Y, Mizushima N, Ueno T, Yamamoto A, Kirisako T, Noda T, Kominami E, Ohsumi Y, Yoshimori T: LC3, a mammalian homologue of yeast Apg8p, is localized in autophagosome membranes after processing. EMBO J 2000, 19:5720-5728

29. Muss HB, Thor AD, Berry DA, Kute T, Liu ET, Koerner F, Cirrincione CT, Budman DR, Wood WC, Barcos M, Henderson IC: C-erbB-2 expression and response to adjuvant therapy in women with nodepositive early breast cancer. N Engl J Med 1994, 330:1260-1266

30. Laemmli UK: Cleavage of structural proteins during the assembly of the head of bacteriophage T4. Nature 1970, 227:680-685

31. Lowry $\mathrm{OH}$, Rosebrough NJ, Farr AL, Randall RJ: Protein measurement with the Folin phenol reagent. J Biol Chem 1951, 193:265-275

32. Li JL, Sainson RC, Shi W, Leek R, Harrington LS, Preusser M, Biswas S, Turley H, Heikamp E, Hainfellner JA, Harris AL: Delta-like 4 North ligand regulates tumor angiogenesis, improves tumor vascular function, and promotes tumor growth in vivo. Cancer Res 2007, 67:11244-11253

33. Ling YM, Shaw MH, Ayala C, Coppens I, Taylor GA, Ferguson DJP, Yap GS: Vacuolar and plasma membrane stripping and autophagic 
elimination of Toxoplasma gondii in primed effector macrophages. $J$ Exp Med 2006, 203:2063-2071

34. Folkman $\mathrm{J}$ : What is the evidence that tumors are angiogenesis-dependent? J Natl Cancer Inst 1990, 82:4-6

35. Weinhouse S: The Warburg hypothesis fifty years later. Z Krebsforsch Klin Onkol Cancer Res Clin Oncol 1976, 87:115-126

36. DeBerardinis RJ, Lum JJ, Hatzivassiliou G, Thompson CG: The biology of cancer. Metabolic reprogramming fuels cell growth and proliferation. Cell Metab 2008, 7:11-20

37. Ganapathy V, Thangaraju M, Prasad PD: Nutrient transporters in cancer: relevance to Warburg hypothesis and beyond. Pharmacol Ther 2009, 121:29-40

38. Yen W-L, Klionsky DJ: Atg27 is a second transmembrane cycling protein. Autophagy 2007, 3:254-256

39. Blommaart EFC, Luiken JJFP, Meijer AJ: Autophagic proteolysis: control and specifity. Histochem J 1997, 29:365-385

40. Kissová I, Deffieu M, Manon S, Camougrand N: Uth1p is involved in the autophagic degradation of mitochondria. J Biol Chem 2004, 279:39068-39074

41. Mortimore GE, Poso AR: Intracellular protein catabolism and its control during nutrient deprivation and supply. Annu Rev Nutr 1987, 7:539-564

42. Martinet W, De Meyer GRY, Andries L, Herman AG, Kockx MM: Detection of autophagy in tissue by standard immunohistochemistry Autophagy 2006, 2:55-57

43. Mizushima N: Methods for monitoring Autophagy. Int J Biochem Cell Biol 2004, 36:2491-2502

44. Motyl T, Gajkowska B, Zarzynska J, Gajewska M, Lamparska-Przybysz $\mathrm{M}$ : Apoptosis and autophagy in mammary gland remodelling and breast cancer chemotherapy. J Physiol Pharmacol 2006, 57[Supp 7]:17-32

45. Reggiori F, Tucker KA, Stromhaug PE, Klionsky DJ: The Atg1-Atg13 complex regulates Atg9 and Atg23 retrieval transport from the preautophagosomal structure. Dev Cell 2004, 6:79-90

46. Webber JL, Young ARJ, Tooze SA: Atg9 trafficking in mammalian cells. Autophagy 2007, 3:54-56

47. He C, Klionsky DJ: Atg9 trafficking in autophagy-related pathways. Autophagy 2007, 3:271-274

48. Legakis JE, Yen Wei-Lien, Klionsky DJ: A cycling protein complex required for selective autophagy. Autophagy 2007, 3:422-432

49. Kuma A, Matsui M, Mizushima N: LC3, an autophagosome marker, can be incorporated into protein aggregates independent of autophagy. Caution in the interpretation of LC3 localization. Autophagy 2007, 3:323-328

50. Marx J: Autophagy: is it cancer's friend or foe? Science 2006, 312:1160-1161

51. Furuya D, Tsuji N, Yagihashi A, Watanabe N: Beclin 1 augmented cis-diamminedichloroplatinum induced apoptosis via enhancing caspase-9 activity. Exp Cell Res 2005, 307:26-40

52. Daniel F, Legrand A, Pessayre D, Vadrot N, Descatoire V, Bernuau D: Partial Beclin 1 silencing aggravates doxorubicin- and Fas-induced apoptosis in HepG2 cells. World J Gastroenterol 2006, 12:2895-2900

53. Ahn $\mathrm{CH}$, Jeong EG, Lee JW, Kim SH, Yoo NJ, Lee SH: Expression of beclin-1, an autophagy-related protein, in gastric and colorectal cancers. APMIS 2007, 115:1344-1349

54. Baehrecke EH: Autophagy: dual roles in life and death? Nat Rev Mol Cell Biol 2005, 6:505-510

55. Edinger AL, Thompson CB: Death by design: apoptosis, necrosis and autophagy. Curr Opin Cell Biol 2004, 16:663-669

56. Kondo Y, Kanzawa T, Sawaya R, Kondo S: The role of autophagy in cancer development and response to therapy. Nat Rev Cancer 2005, 5:726-734

57. Liang XH, Yu J, Brown K, Levine B: Beclin 1 contains a leucine-rich nuclear export signal that is required for its autophagy and tumor suppressor function. Cancer Res 2001, 61:3443-3449

58. Liang XH, Kleeman LK, Jiang HH, Gordon G, Goldman JE, Berry G Herman B, Levine B: Protection against fatal Sindbis virus encephalitis by beclin, a novel Bcl-2-interecting protein. J Virol 1998, 72:8586-8596

59. Liang XH, Jackson S, Seaman M, Brown K, Kempkes B, Hibshoosh H Levin B: Induction of autophagy and inhibition of tumorigenesis by beclin 1. Nature 1999, 402:672-676

60. Miracco C, Cosci E, Oliveri G, Luzi P, Pacenti L, Monciatti I, Mannucci S, De Nisi MC, Toscano M, Malagnino V, Falzarano SM, Pirtoli L, Tosi $\mathrm{P}$ : Protein and mRNA expression of autophagy gene Beclin 1 in human brain tumours. Int J Oncol 2007, 30:429-436

61. DiPaola RS, Dvorzhinski D, Thalasila A, Garikapaty V, Doram D, May M, Bray K, Mathew R, Beaudoin B, Karp C, Stein M, Foran DJ, White $\mathrm{E}$ : Therapeutic starvation and autophagy in prostate cancer: a new paradigm for targeting metabolism in cancer therapy. Prostate 2008 , 68:1743-1752

62. Novikoff $A B$, Shin WY: Endoplasmic reticulum and autophagy in rat hepatocytes. Proc Natl Acad Sci U S A 1978, 75:5039-5042

63. Miyata S, Takemura G, Kawase Y, Li Y, Okada H, Maruyama R, Ushikoshi H, Esaki M, Kanamori H, Li L, Misao Y, Tezuka A, Toyo-Oka T, Minatoguchi S, Fujiwara T, Fujiwara H: Autophagic cardiomyocyte death in cardiomyopathic hamsters and its prevention by granulocyte colony-stimulating factor. Am J Pathol 2006, 168:386-397

64. Vincent RA Jr, Spicer SS: Giant dense bodies in fibroblasts cultured from beige mice with Chediak-Higashi syndrome. Am J Pathol 1981, 105:270-278

65. Klionsky DJ: The molecular machinery of autophagy. Unanswered questions J Cell Sci 2005, 118:7-18 